patients with a progressive than those with a remittent onset. Overall, a late onset of the disease, a short interval between the first two relapses, and the occurrence of the progressive phase were all associated with a poor outcome.

${ }^{1}$ Millar JHD. Multiple sclerosis: introduction. Br Med Bull 1977;33:1-3.

${ }_{2}$ McAlpine D. Course and prognosis. In: McAlpine D, Lumsden CE, Acheson ED, eds. Multiple sclerosis: a reappraisal. 2nd ed. London: Churchill, 1972:197-223.

${ }^{3}$ Georgi W. Multiple sclerose : pathologisch-anatomische Befunde multipler sklerose bei klinisch nicht diagnostizierten Krankheiten. Schweiz Med Wochenschr 1961 ;91:605-7.

4 Mackay RP, Hirano A. Forms of benign multiple sclerosis. Report of two "clinically silent" cases discovered at autopsy. Arch Neurol 1967;17: $588-600$.

5 Confavreux C, Aimard G, Devic M. Course and prognosis of multiple sclerosis assessed by the computerized data processing of 349 patients. Brain 1980;103:281-300.

${ }^{6}$ McAlpine D. The benign form of multiple sclerosis. A study based on 241 cases seen within three years of onset and followed up until the tenth year or more of the disease. Brain 1961;84:186-203.

${ }^{7}$ Leibowitz U, Alter M. Multiple sclerosis. Clues to its cause. Amsterdam: North Holland Publishing Company, 1973.

${ }^{8}$ Anonymous. Benign type of disseminated sclerosis. $\mathrm{Br} \mathrm{Med} \mathcal{F}$ 1962; ; :780.

\section{BCG in Britain}

Tuberculosis is almost always transmitted by the airborne route. In Britain today chemotherapy is the most successful tactic used against this mode of spread, rapidly rendering patients whose sputum contains Mycobacterium tuberculosis non-infectious. Chemotherapy may be backed by chemoprophylaxis in those infected (tuberculin positive without prior BCG vaccination) but disease free, thus reducing the numbers later becoming infectious to others. For specific prophylaxis vaccination with BCG is offered to certain groups of people who have not been infected naturally. These groups include contacts of active cases, 10-13-year-old schoolchildren, and those at high risk of infection such as some hospital personnel. Is this use of BCG reasonable?

The effectiveness of BCG vaccination in British schoolchildren is not in doubt. In the controlled trial organised by the Medical Research Council in 1950-2 vaccination led to a $77 \%$ reduction in the incidence of tuberculosis over a 20 -year period, though 10-15 years after vaccination protection dropped to $59 \%$ and after this no valid comparison could be made because of the low incidence of disease in both test and control groups. ${ }^{1}$ Neither miliary tuberculosis nor tuberculous meningitis was seen in the test group whereas 10 cases occurred in the controls, and all other forms of tuberculous disease were reduced. ${ }^{2}$ More recent evidence suggests that from 1967 to 1976 the school BCG programme continued to offer more than $70 \%$ protection for at least 10 years. ${ }^{3}$ Neither study tried to assess how race or place of birth may modify this protection and, in view of the variation in protection-from zero to $80 \%$ -in BCG trials worldwide no extrapolations should be made.

Extensive experience has shown that BCG vaccination is one of the safest vaccinations, ${ }^{4}$ though complications at the site of injection include prolonged ulceration and subcutaneous abscess, and the draining lymph nodes occasionally suppurate. These complications occur more frequently in neonates and infants and are related to the dose and possibly to the strain used. Disseminated infection is rare.

The estimated total cost of a vaccination in the school programme at June 1975 prices was $99 \mathrm{p} .{ }^{5}$ This is not expensive, but even with favourable assumptions calculations showed that by the early 1980s the school programme would be four times more expensive than stopping vaccination and treating the resulting cases of tuberculosis. The difference in costs will increase further if recent advice about reducing the length of hospital stay is widely followed. ${ }^{6}$ Moreover, a consequence of BCG administration is tuberculin sensitivity for a variable period, and this devalues the later use of tuberculin testing both as an aid to individual diagnosis and as an epidemiological tool. It would also preclude the use of chemoprophylaxis on a scale as wide as that recommended in the United States. ${ }^{7}$

Thus BCG vaccination is safe, protective, and cheap, though the school programme does not pay its way financially. Who then should receive it? On the unproved assumption that the effectiveness of BCG in British schoolchildren will be mirrored in the general population, vaccination might reasonably continue to be offered to tuberculin-negative people in highrisk groups, including contacts and hospital and laboratory workers. We have long appreciated that the school programme has a limited lifespan in view of the decreasing incidence of tuberculosis, although pockets of relatively higher incidence remain. There were 6810 notifications of respiratory tuberculosis in England and Wales in 1979, a further decrease of $3.6 \%{ }^{8}$ For each 100000 BCG vaccinations given in the programme during 1979, an estimated 44 cases of notified tuberculosis will be prevented over the next 15 years. ${ }^{3}$ This is not the cheapest way of managing tuberculosis, but how can we price the value of a prevented case? Emotional decisions are inevitable, but the school programme could reasonably be stopped in areas of the country where the likelihood of contact with the disease is minimal.

As a report of an outbreak of tuberculosis in the West Midlands in 1979 shows, the use of the tuberculin test in children who have not yet received BCG vaccination combined with intensive contact tracing can define and help control an outbreak. ${ }^{9}$ Discussion of the role of BCG vaccination should not be allowed to detract from the emphasis placed on the diagnosis of patients with symptoms, the search for infected individuals without symptoms, and the effective treatment of both.

${ }^{1}$ Hart PD'A, Sutherland I. BCG and vole bacillus vaccines in the prevention of tuberculosis in adolescence and early adult life. Final report to the Medical Research Council. Br Med f 1977;ii:293-5.

2 Fourth report to the Medical Research Council by its tuberculosis vaccines clinical trials committee. BCG and vole bacillus vaccines in the prevention of tuberculosis in adolescence and early adult life. Bull WHO $1972 ; 46: 371-85$.

${ }^{3}$ A report from the research committee of the British Thoracic Association. Effectiveness of BCG vaccination in Great Britain in 1978. $\mathrm{Br} \mathcal{F} \mathrm{Dis}$ Chest (in press).

${ }^{4}$ ten Dam HG, Toman K, Hitze KL, Guld J. Present knowledge of immunization against tuberculosis. Bull WHO 1976;54:255-69.

5 Stilwell JA. Benefits and costs of the schools' BCG vaccination programme. Br Med F 1976; : 1002-4.

${ }^{6}$ Anonymous. Isolation of patients with pulmonary tuberculosis. $\mathrm{Br} \mathrm{Med} \mathcal{F}$ 1980;280:962-3.

7 American Thoracic Society. Preventive therapy of tuberculous infection. Am Rev Respir Dis 1974;110:371-4.

${ }^{8}$ Office of Population Censuses and Surveys. Deaths and corrected notifications of selected diseases. Office of Population Censuses and Surveys Monitor 1980;MB 2 80/2:3.

${ }^{9}$ Rao VR, Joanes RF, Kilbane P, Galbraith NS. Outbreak of tuberculosis after minimal exposure to infection. $\mathrm{Br} \mathrm{Med} \mathcal{F} 1980 ; 281: 187-9$. 